\title{
The rheological modification of the Daura asphalt in polycarbonate using the microwave technique
}

\author{
Salam Jajo Marzina ${ }^{*}$, Khalid Ahmed Owaid ${ }^{2}$ \\ ${ }^{1,2}$ Department of Chemistry, College of Education for Pure Sciences, University of Mosul, Mosul, Iraq \\ E-mail: ${ }^{1 *}$ Khalid.a.waid73@gmail.com, ${ }^{2}$ salamkarash@gmail.com
}

(Received March 09, 2020; Accepted May 01, 2020; Available online December 01, 2020)

DOI: 10.33899/edusj.2020.126779.1054, (c) 2020, College of Education for Pure Science, University of Mosul.

This is an open access article under the CC BY 4.0 license (http://creativecommons.org/licenses/by/4.0/).

\begin{abstract}
:
This study has included a modulation of the rheological properties of asphalt by a catalyst chemical treatment with polycarbonate, and the microwave technique was used at a power of (360) watt at time intervals. Furthermore, the modulation and treatment were done in the presence of sulfur and polycarbonate. The formed rheological properties of the new asphalt samples were studied which include (permeability, softening point, ductility and penetration index). Those asphalt samples of the new rheological properties could be used in paving field and some other samples could be used as antimoisture materials.

The best asphalt samples with new rheological properties and those conformable with the properties of roads authority and Iraqi bridges were tested as a tiled asphalt since they were studied in terms of conducting Marshall tests and comparing them with the original sample in order to show the possibility of using the modified samples in the tiling and the obtained results were excellent in terms of stable creeping values. In addition the aging test was applied on the samples that contain good rheological properties.

Moreover, the modified asphalt has shown higher dissociation values in comparison with the original asphalt, so the modified asphalt has more resistant to high temperature and acid rains and shows an important characteristic of the quality of the asphalt that enables the modified asphalt to stick more closely to the aggregate, which gives higher resistance and greater operating age life to the streets.
\end{abstract}

Keywords: polymers, asphalt, additives.

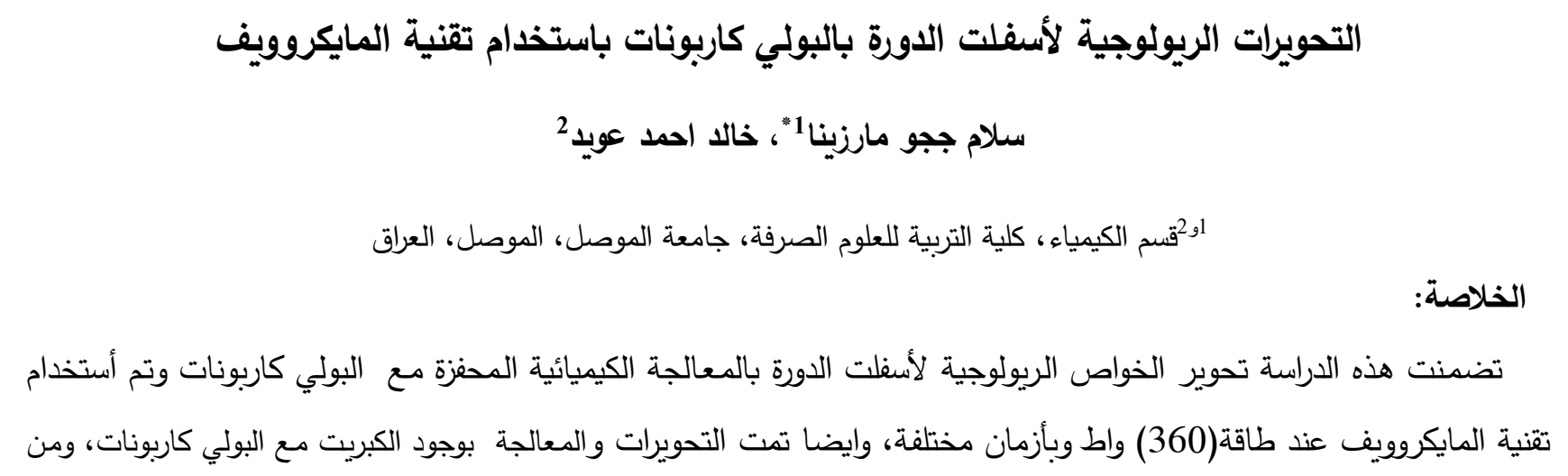




\section{Journal of Education and Science (ISSN 1812-125X), Vol: 29, No: 4, 2020 (1-21)}

ثم تم دراسة الخواص المريولوجية الناتجة من حيث (النفاذية، درجة الليونة، الاستطالة ودليل الاختراق)، حيث تم الحصول على نماذج أسفلتية ذات مواصفات ريولوجية يمكن استخدامها في مجال التبليط وأخرى يمكن استخدامها كموادٍ مانعةٍ للرطوبة.

وبعدها اختبرنا أفضل النماذج الأسفلتية وذات المواصفات الريولوجية المطابقة لمواصفات هيئة الطرق والجسور العراقية كأسفلت تبليط اذا تمت دراستها من حيث إجراء اختبارات مارشال ومقارنتها مع النموذج الاصل من أجل بيان إمكانية استخدام النماذج المُحور في التبليط وكانت النتائج المحصل عليها ممتازة من حيث قيم الزحف الاستقرارية، كما وأجري أيضاً اختبار التقادم على النموذج ذات المواصفات الريولوجية الجيدة.

وفضلاً عن ذلك فإن الأسفلت المُحور يمتلك قيم انسلاخٍ أعلى من أسفلت الأصل بذلك سوف يكون الأسفلت الدحور أكثر مقاومة لدرجات الحرارية العالية والأمطار الحامضية حيث تعتبر خاصية مهمةً في نوعية الأسفلت التي تمكن الأسفلت المُحور من الالتصاق بصورة أكبر مع الركام مما يعطي مقاومة عالية وعمر تشغيلي أكبر للشوارع. الكلمات المفتاحية: البوليمرات ، الأسفلت ، المضافات.

\section{Introduction}

أولا:- المقــــــة

يعرف الأسفلت بأنه مادة سائلة ثقيلة ذات لزوجة عالية حتى تصل حدود الصلابة عند انخفاض درجات الحرارة، حيث يتكون الأسفلت بدرجة رئيسية من مركبات هيدروكاربونات بارافينية ونفثينية وارومية، كما يشتمل على مركبات حلقية أو غير حلقية تحتوي

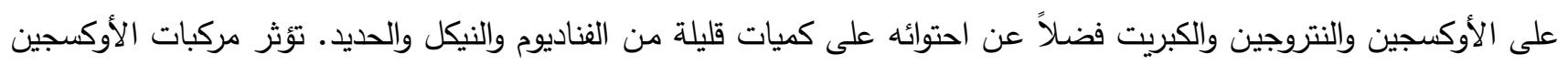
والنتروجين والكبريت مع العناصر المعدنية تأثيرات مهمة في الصفات الفيزيائية للأسفلت، إذ تعمل العناصر المعدنية القطبية على زيادة التداخل بين الجزئيات وتؤثر في الذوبانية ودرجة الغليان واللزوجة. يكون لون الأسفلت عادة اسوداً وينتج من عملية تقطير النفط الخام، حيث يتخلف من أبراج التقطير بهيئة مادة ثقيلة بعد أن يتم سحب المواد المتطايرة والخفيفة[2,1].

وهناك تعريف آخر يمكن اعطاء للأسفلت بأنه تلك المادة البتيومينية الثقيلة التي تبقى بعد إزالة المشتقات الخفيفة القابلة للتقطير والتطاير من الأجزاء النفطية[3].

ويعرف الأسفلت بعدة مُسمياتٍ حول العالم، إذ يستخدم مصطلح بتيومين(Bitumen) في أوربا وهو مرادف لكلمة أسفلت في أمريكا الثمالية، أما خارج أمريكا الثمالية فيستخدم مصطلح أسفلت للدلالة على مخاليط البتيومين مع المواد المعدنية[4]

يمتاز الأسفلت بلونه الأسود أو البني الغامق وبوزنه الجزيئي العالي عند مقارنته مع أجزاء اخرى من النفط الأخرى وبكثافته

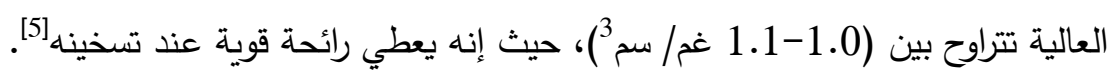




\section{Journal of Education and Science (ISSN 1812-125X), Vol: 29, No: 4, 2020 (1-21)}

وإن الخمول الكيميائي الذي يمتاز به الأسفلت والمتوافق مع خواصه الفيزيائية هو الأمر الذي يجعله مؤهلاً لاستعمالات واسعة في الصناعة والبناء منذ القديم الزمن. وإن طبيعة الصفات الفيزيائية له هي التي تحدد طبيعة الاستعمال أكثر من تلك الكيميائية، وذلك بسبب استخدامه والمواد المصنَعَة منه في التطبيقات والأعمال الهندسية [6,5]. وإن أول من اقترح فكرة إضافة المطاط المستهلك(Waste rubber) كمادة محورة للأسفلت هو العالم Mcdonald إذ تمت إضافة مطاط الإطارات التالفة بطريقتين وكلتاهما تتضمن تثكيل المطاط بأبعاد صغيرة لاتتجاوز (25 mm) وبنسب مطاط بين (18-25) للطريقة الرطبة Wet) (process) و(0.5-5) للطريقة الجافة (Dry process)، والاختلاف الجوهري بين هاتين الطريقتين هو أنه في الطريقة الأولى تمزج حبيبات المطاط مع الأسفلت بحدود حرارية (175- 200)ْ ولمدة (1-2)ساعة، بعدها يمزج مع الحصى والرمل، في حين تمزج الحبيبات المطاطية مع الرمل والحصى في الطريقة الجافة وتضاف مباشرة إلى أسفلت التبليط الساخن، ولاحظ أن هذه الخلائط لها عمر اقصر في خدمات التبليط مقارنة مع الأسفلت غير المعالج ، إلا أنه يمكن استخدام المزيج المحضر بالطريقة الرطبة لتغطية طبقات الطرق القديمة والمعرضة إلى إجهادات، ولاحظ أنها تعطي خصائص الأسفلت الكونكريتي نفسه، إن دور المطاط في هاتين الطريقتين يكون كمواد مالئة(filler)، أي يبقى المطاط محافظاً على تركيبه الثبكي المفلكن ولا يحصل له ذوبان أو إزالة

وقد تمكنت Murshid [8 من تحسين المعاملة الحرارية لطبقة التغطية السطحية من الرصف اللين و تحسين الخلطات البتيومينية إذ استخدمت الأسفلت المعدل بالبوليمرستايرين بيوتادايين ستايرين (SBS) إذ أظهرت النتائج تحسناً من ناحية مقاومة هذه الخلطات المحضرة تجاه التأثر الحراري الذي تتعرض له.

وتمكنت Abbas [9] وجماعتها من تحسين المقاومة الحرارية وتقليل تأثير الاهتزازات في الخلطة الأسفلتية باستعمال مفروم الإطارات المستهلكة والبوليمرات إذ تمت إضافة مادة النوفولاك بنسب مختلفة من وزن أسفلت الدورة مع إضافة مفروم الاطارات المستهلكة بنسب لهاب مختلفة من وزن أسفلت الدورة وقد كانت النتائج بعد إجراء الفحوصات جيدة من ناحية زيادة قوة الثبات وانخفاض في قيمة السحب والاختراق للأسفلت المحسن.

وتمكن Muhammed [10] من تحوير الخواص الريولوجية لأسفلت القيارة باستعمال الموجات فوق الصوتية وباستعمال مطاط الإطارات المعاد بنسب وزنية مختلفة وبوجود حفاز كلوريد الألمنيوم اللامائي بنسب وزنيه مختلفة مع نسب وزنية مختلفة من الكبريت(S) ومن ثم دراسة الخواص الريولوجية الناتجة من حيث الاستطالة، درجة الليونة، النفاذية ودليل الاختراق. وأخذ أفضل النماذج من حيث الخواص الريولوجية والمطابق لمواصفات هيئة الطرق والجسور العراقية كأسفلت تبليط وأجريت عليه اختبار مارشال

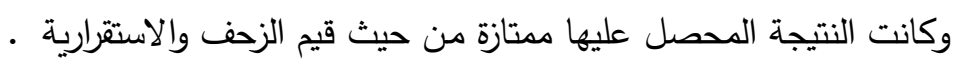

وقد استطاع nekhoroshev عليها عن طريق البلمرة ، حيث تم العملية الاضافة عند 140ْم حيث أدى ذلك الى اكسدة APP مما أدى الى انتاج أسفلت مقاوم للتدهور الحراري والتقادم والالتصاق العالي. 


\section{Journal of Education and Science (ISSN 1812-125X), Vol: 29, No: 4, 2020 (1-21)}

وفي بحثاً اخر [12] تم تحوير مواصفات الأسفلت بالمعالجة الكيميائية والفيزيائية ، باضافة الكبريت مع نسب مختلفة من راتتج الفينول - فورمالديهيد وزيت المستهلك حيث تم الحصول من خلال هذه الدراسة على نماذج أسفلتية ذات مواصفات ريولوجية جيدة من ناحية التبليط وايضأ تم الحصول على نماذج يمكن استخدامها كمواد مانعة للرطوبة اعتماداً على القياسات التي تم أجرائها (النفاذية والليونة والاستطالة ودليل الاختراق ).

ودرس Sultan ${ }^{[3]}$ اضافة بولي بروبلين بنسب مختلفة الى البتيومين (60-70) حيث تهدف هذه الدراسة الى زيادة مقاومة الأسفلت لدرجات الحرارة المرتفعة وزيادة ممانعته للظروف المناخية المختلفة ، حيث تم اجراء الاختبارات على العينات البتيومين المعدل والتي تضمنت الاستطالة والنفاذية وحساب دليل الاختراق ودرجة الليونة ،واستخدم فرن الطبقة الرقيقة الدوار (RTFOT).

وقام Yu بنتين) وبولي (انهيدريد الماليك -Co- اكريلونتريل) وبولي (انهيدريد الماليك -Co- اندين) باستخدام الكبريت حيث أدى ذلك الى زيادة اللزوجة والحساسية الحرارية وزيادة تماسك الأسفلت وزيادة مقاومة التشوه الدائم وتحسين في مقاومته تأثره بدرجات الحرارة المنخفضة.

حيث تمكن Lin[15] وجماعته من تحسين أداء خصائص الأسفلت باستخدام اكياس النفايات السريعة (WEBs) والتي يصعب تدويرها ،حيث اظهرت النتائج هذا التحوير زيادة في اللزوجة وتقلل من الاختراق والليونة ، واظهرت نتائج التحليل الطيفي للاشعة تحت الحمراء أن التعديل كان عبارة عن تعديل فيزيائي دون تفاعل كيميائي.

أما Yu [16] وجماعته تمكنا من زيادة استقرار التخزين لأسفلت المطاطي AR وايضاً من التغلب على ضعف قابلية التشغيل لأسفلت المطاطي من خلال اضافة النفط الحيوي الثقيل (HBO)، حيث تم اجراء سلسلة من الاختبارات على الأسفلت وتبين هنالك مقاومة عالية للتقادم مقارنة مع أسفلت الامطاطي AR.

وفي بحثاً اخر [17] تم تحوير الخواص الريولوجية للأسفلت باستخدام الزيوت المستهلكة والآكسدة الهوائية، وقد تم الحصول من خلال هذه الدراسة على نماذج أسفلتية ذات مواصفات ريولوجية بالإمكان استعمالها في مجال التبليط والنماذج أخرى يمكن استعمالها كمواد مانعة للرطوبة اعتمادا على القياسات التي تم إجراؤها(الاستطالة, النفاذية , درجة الليونة , حساب دليل الاختراق ونسبة الأسفلتين). وتمكن kharandi وجماعته[18] من تحوير الخواص الفيزيولوجية والريولوجية عند درجة حرارة العالية للبتيومين من خلال اضافة هيدروكسي ايثيل ميثاكريلات (PHEMA) بكميات مختلفة ،حيث كانت العينات عبارة عن مخاليط متجانسة ، واظهرت النتائج تحسين في مقاومة التشوه الدائم للأسفلت في درجات الحرارة العالية، ومع استقرار التخزين بشكل مقبول، وذلك من خلال الاختبارات متعددة منها المسح الضوئي وفرن الأغثية الرقيقة والنفاذية والليونة واللزوجة. 


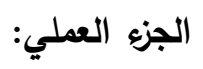

اولا:- المواد المستعملة: (Materials Used)

1-أسفلت الدورة الخام المنتج في مصفى الدورة يتميز هذا الأسفلت بالمواصفات الموضحة في الجدول(1).

الجدول (1):- الخواص الفيزيائية العامـة لأسفلت الدورة.

\begin{tabular}{|c|c|}
\hline القيمة & الخواص الفيزيائية العامة \\
\hline 50 & درجة الليونة (مº) \\
\hline 44.6 & النفاذية (100غم، 5 ثا ، 25مم) \\
\hline $100+$ & الاستطالة (سم، 25 مº) \\
\hline-1.448 & دليل الاختراق(PI) \\
\hline$\% 17.81$ & نسبة الأسفلتين \\
\hline
\end{tabular}

2- حفاز كلوريد الألمنيوم اللامائي المُجهز من شركة Fluka.

3- الكبريت إذ تم الحصول عليه من الثركة العامة لكبريت المشراق.

4- بولي كاربونات المحصل عليه من تكسير اقراص الـCD.

Instruments Used

Ductility
ثانيا: الأجهزة المستخدمة

1 - 1 - 1 - 1هاز قياس الاستطالة

يعمل هذا الجهاز على قياس المسافة التي تستطيل بها المواد الأسفلتية عند تعرضها لتأثير سحبٍ وبسرعةٍ ثابتة، إلى أن ينقطع الأنموذج الأسفلتي. والجهاز ذو منشأ صيني من نوع(YUFENG).

\section{Penetrometer}

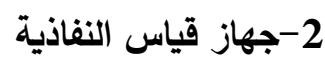

يعمل الجهاز على فحص نفاذية المواد البتيومينيـة الصلبـة وشبـه الصلبـة. فالنفاذيـة هي مقياس لصلابـة الأسفلت. والجهاز ذو منشأ صيني نوع(YUFENG).

Ring and Ball Apparatus

3-جهاز قياس درجة الليونة 
يعمل هـذا الجهـاز على قيـاس درجة الليونة للمواد الأسفلتية التي تتراوح ليونتها ما بين (30-200)خ، ودرجة الليونة هي الدرجة الحرارية التي ينزل عندها الأنموذج الأسفلتي مسافة (2.54)سم عند تسخينه بسرعة (5م/ دقيقة) مع تجنب التسخين السريع(Fast heating).

Polymer Treated Asphalt Apparatus

4 - جهاز معالجة الأسفلت بالمضافات

يتكون الجهاز من الأجزاء الآتية :

• دورق زجاجي كبير بحجم 200مل ثلاثي الفتحات (Three Necked Flask).

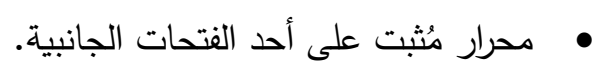

• مُسخن كهربائي (Electrical Mental) مُزود بمنظم (Regulator) للسيطرة على درجة الحرارة.

$$
\begin{aligned}
& \text { • محرك ميكانيكي يُثبت على الفتحة الوسطى للدورق • } \\
& \text { • امل حديدي مُزود بماسك لتثبيت الدورق. }
\end{aligned}
$$

Microwave Oven

5

استخدم فرن المايكروويف ذو المنشأ الألماني من نوع(Tokiwa) وبقدرة (900 واط) وتردد(2450) MHz في عملية تحضير النماذج الأسفلتية المحورة.

\section{Electrical shaker}

$$
6
$$

Hamber Ggo Shaker استخدم هذا الجهاز لرج محلول (أسفلت -هكسان اعتيادي) لغرض فصل الأسفلت، وهو من نوع .Germany

\section{Marshall Testing Apparatus}

7 -

هذا الفحص يعطي دلالة عن مدى ملائمة الأسفلت للتبليط ، والجهاز ذو منشأ إنكليزي نوع (FREHAM

.(FARRANCE

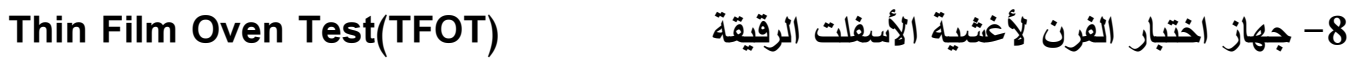

يُبين هذا الفحص مدى تأثر أسفلت التبليط المُحور بظروف التقادم الزمني(Aging)، والجهاز ذو منشأ ياباني مُوديل(710812). 
ثالثاً :- طريقة العمل: (Experimental Method) 1- التحليل الحراري الوزني للبوليمرات:-

تم أخذ وزن معلوم من البولي كاربونات بعد تكسيره جيداً إلى قطع صغيرة ووضع في جفنة خزفية مغطاة برقائق الألمنيوم, ثم عُوملت الجفنة حرارياً عند مدى حراري تراوح بين (50-500) مم وبزيادة (50) م لكل قراءة, إذ تم تحديد درجة الحرارة الملائمة والمثلى لتكسير (تهشيم) كل بوليمر • وكانت النتائج المحصل عليها حسب الجدول (2) والثكل (1) يُوضح منحنى التحليل الحراري الوزني للبولي كاربونات.

2- تحوير الخواص الريولوجية للأسفلت بالمعالجة الكيميائية المحفزة مـع بولي كاربونات باستخدام تقنية المايكروويف:-

وزنَ (250) غم من أسفلت الدورة الأصل ووضع في جهاز معالجة المادة الأسفلتية ، وسُخن إلى درجة حرارة (100)مْ، بعدها تمت إضافة (0.5)\% من بولي كاربونات، ومن ثم تم إضافة كلوريد الألمنيوم اللامائي كحفاز بعد أن تم تنقيتهُ آنياً وبنسبة (0.06)\%، ومزجت المادة المتفاعلة بصورة جيدة ورفعت درجة حرارة المزيج إِلى (150)مْ مع استمرار الرج لمدة

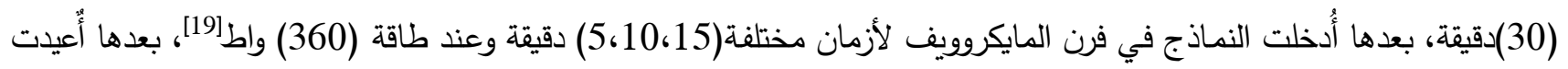
التجربة باستخدام نسب وزنية مختلفة من البولي كاربونات (1,2,3) \% .

بعدها أجرينا عـــى النــــاذج المحضرة قياسات الاستطالة[20]، النفاذية[21]، درجــة الليونة [22]دليل الاختراق[23]، وكانت النتائج المحصل عليها حسب الجدول (3).

3- تحوير الخواص الريولوجية للأسفلت بالمعالجة الكيميائية المحفزة بوجود الكبريت مـع بولي كاربونات باستخدام تقنية المايكروويف:

أعيدت نفس خطوات الفقرة (2) من الجزء العملي ولكن مع اضافة 1\% كبريت، وكانت النتائج المحصل عليها حسب الجدول (4). 4- تحوير الخواص الريولوجية للأسفلت بالمعالجة الكيميائية المحفزة مـع بولي كاربونات بدون استخدام تقنية المايكروويف: وزنَ(250) غم من أسفلت الدورة الأصل ووضع في جهاز معالجة المادة الأسفلتية ، وسُخن إلى درجة حرارة(100)مْ؛ بعدها تمت إضافة (0.5)\% من بولي كاربونات ، وبعدَ ذلك تم إضافة كلوريد الألمنيوم اللامائي كحفاز بعد أن تمت تنقيتهُ آنياً وبنسبة (06.06)؛ ومزجت المادة المتفاعلة بصورة جيدة ورفعت درجة حرارة المزيج إلى(150)مْ مع استمرار الرج لمدة (30) دقيقة،

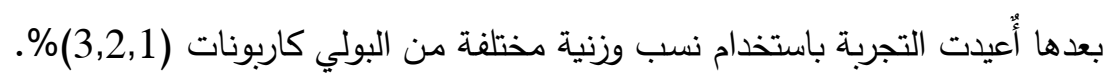
بعدها أجرينا علــى النـــاذج المحضرة قياسات الاستطالة]20]، النفاذية]21]، درجــة الليونة [22] ودليل الاختراق[23]، وكانت النتائج المحصل عليها حسب الجدول (5). 
يبينُ هذا الفحص مدى قابلية التصاق الأسفلت بالركام ومقاومته لارجات الحرارة العالية والأمطار الحامضية. ويتضمن هذا الفحص وضع الأسفلت الممزوج مع الركام في دورق زجاجي سعة(200)مل ويوضع فيه (50)مل ماء مقطر مع نسب مختلفة من كاربونات الصوديوم) (Na2 ${ }^{2} \mathrm{CO}_{3}$ ثم يسن الدورق الى درجة الغليان وبعد ذلك يتم رفع الدورق من على التسخين ويترك لمدة دقيقة

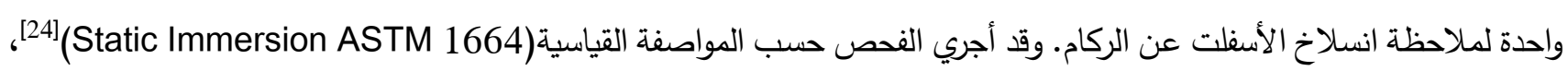
وكانت النتائج المحصل عليها حسب الجدول(6).

\section{6- فحص مارشال (التبليط بالأسفلت): Marshall}

لغرض معرفة مدى ملائكة النماذج الأسفلتية المُحورة والمطابقة للمواصفات هيئة الطرق والجسور العراقية (S.O.R.B) خلال حساب الزحف والاستقرارية للنماذج لكل من الاصل والمُحور وحسب طريقة معهذ الأسفلت الأمريكي [26]، وكانت النتائج المحصل عليها حسب الجدول (7).

7- اختبار الفرن لاغثية الأسفلت الرقيقة: (Thin Film Oven Test) يبين هذا الفحص مدى تأثر أسفلت المُحور بظروف التقادم الزمني , ومقارنته مع النموذج الاصل . وقد اجري الفحص وفق المواصفات القياسية الامريكية(2002-1754 (DSTM (27)، وكما موضح في الجدول (8).

\section{Asphaltene separation}

8

وضست كمية من إسـفلت الدورة الاصـل(1غم ) في داخل وعاء مخروطي ذي غطاء مُحكم وأُضـيف لها (40مل) هكسـان اعتيادي بنسبة (40:1) ( وزن : حجم) ورج المـحلول لمــــــ(3 ساعات) باستخدام جهاز الرج الكهربائي بدرجة حرارة الغرفة وبعدها رُشح المحلول وغُسل المتبقي بالهكسان الاعتيادي إلى أَن تُصبح قطرات الغسل عديمة اللون، ثم جُفف الراسب ووزن بدقة وتحسب النسبة المئوية للراسب (الإسفلتين), وبعدها طبقت عملية فصل الاسفلتين على جميع النماذج المحضرة.

(النتائج والمناقثة : (Results and discussion)

\section{Thermal treatment of Polymers} 1 - المعاملة الحرارية للبوليمرات

عُومل البولي كاربونات المستخدمة في هذه الدراسة حرارياً كما هو موضح في طريقة العمل, إذ إن الدرجة الحرارية المستخدمة في معاملة هذا البوليمر تم الاستدلال عليها من نتائج التحليل الحراري الوزني التي تعطي معلومات عن الدرجات الحرارية التي تبدأ عندها المواد البوليمرية بالتهشم ومقدار الفقدان في وزن البوليمر عند تلك الدرجات الحرارية, إذ إن البولي كاربونات يتكسر عند (350) م. والجدول (2) والثكل (1) يُوضح منحنى التحليل الحراري الوزني للبولي كاربونات. 
Journal of Education and Science (ISSN 1812-125X), Vol: 29, No: 4, 2020 (1-21)

الجدول (2): نتائج التحليل الحراري الوزني للبولي كاربونات.

\begin{tabular}{|c|c|}
\hline الوزن(غم) & درجة الحرارة (مُ0) \\
\hline $1 *$ & 25 \\
\hline 0.9964 & 100 \\
\hline 0.9954 & 150 \\
\hline 0.9937 & 200 \\
\hline 0.9933 & 250 \\
\hline 0.9928 & 300 \\
\hline 0.9904 & 350 \\
\hline 0.9710 & 400 \\
\hline 0.9046 & 450 \\
\hline 0.8548 & 500 \\
\hline
\end{tabular}

الوزن الأصلي

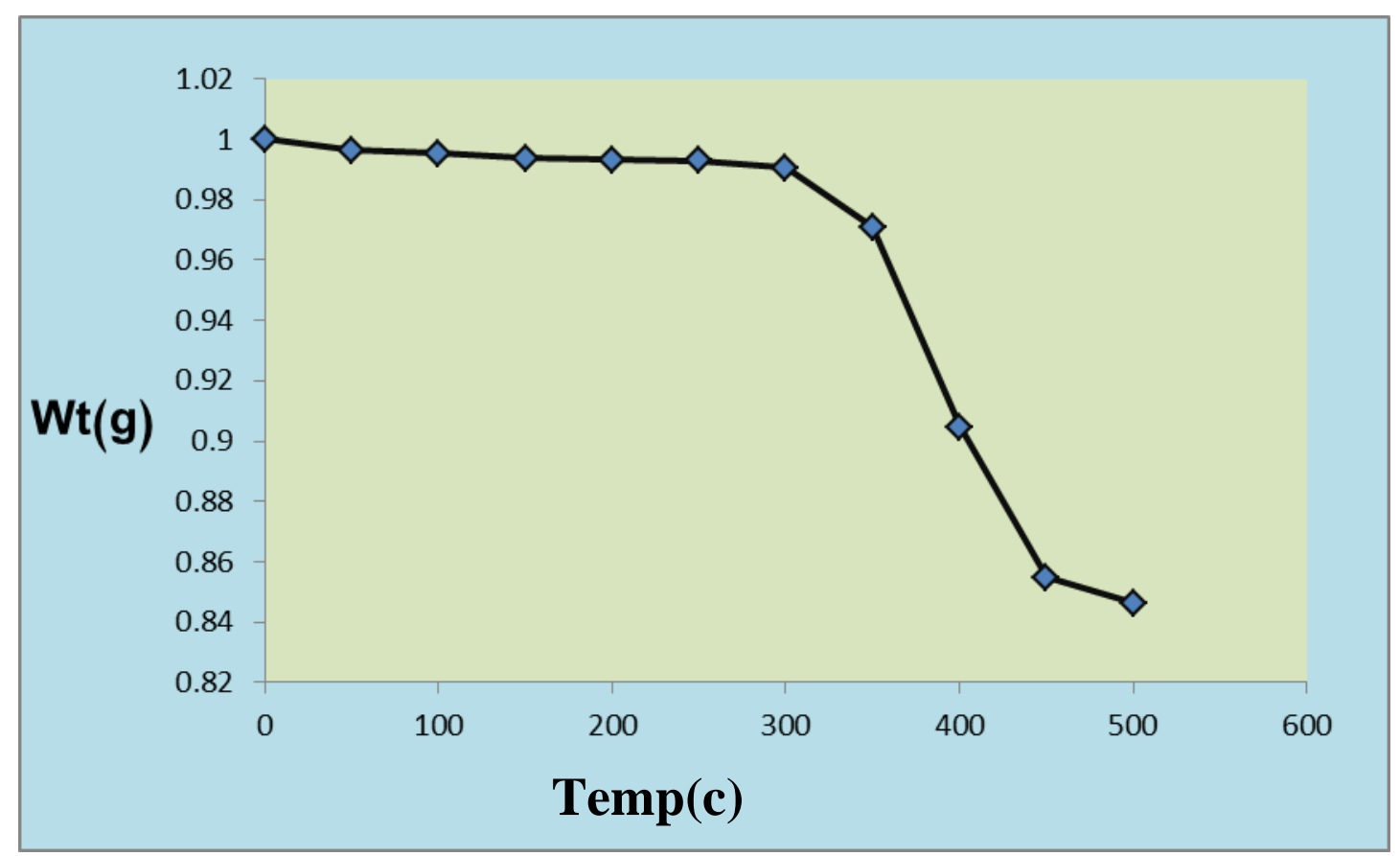

الثكل(1): منحنى التحليل الحراري الوزني لبولي كاربونات. 
2- تحوير الخواص الريولوجية للأسفلت بالمعالجة الكيميائية المحفزة مـع البولي كاربونات باستخدام تقنية المايكروويف :إذ تم مزج أسفلت الاصل مع نسب وزنية مختلفة من البولي كاربونات (3,2,1,0.5)\% والمعد حسب الفقرة (1) من الجزء العملي، وإضافة نسبة (0.06) من حفاز كلوريد الألمنيوم اللامائي وعند طاقة (360) واط وبأزمان مختلفة[19]، وتم إجراء التحوير كما هو مُبين في الفقرة (2) من الجزء العملي، والجدول (3) يوضح النتائج التي تم الحصول عليها .

الجدول (3):- المواصفات الريولوجية لأسفلت الدورة المُحور مـع نسب مختلفة من بولي كاربونات، وبوجود نسبة 0.06\% من حفاز كلوريد الألمنيوم اللامائي وعند طاقة 360 واط وبأزمان مختلفة.

\begin{tabular}{|c|c|c|c|c|c|c|c|}
\hline $\begin{array}{c}\text { الأسفلتين } \\
\text { (\%) }\end{array}$ & $\begin{array}{c}\text { الاختراق } \\
\text { (PI) }\end{array}$ & الليونة & (النفاذية,ملم & الاستطالة & الزمنن & $\begin{array}{c}\text { كاربونات } \\
\text { (wt\%) }\end{array}$ & الانموذج \\
\hline 17.81 & -1.448 & 50 & 44.6 & +100 & 0 & 0 & $\mathrm{As}_{0}$ \\
\hline 19.89 & 0.645 & 60 & 42.7 & +100 & 5 & 0.5 & $A s_{1}$ \\
\hline 21.30 & 1.074 & 63 & 40.2 & +100 & 5 & 1 & $A s_{2}$ \\
\hline 21.94 & 1.380 & 65 & 39.3 & +100 & 5 & 2 & $A s_{3}$ \\
\hline 24.16 & 1.446 & 66.5 & 36.1 & 78 & 5 & 3 & $\mathrm{As}_{4}$ \\
\hline 20.68 & 0.968 & 62 & 41.6 & +100 & 10 & 0.5 & $\mathrm{As}_{5}$ \\
\hline 20.52 & 0.940 & 61.5 & 42.8 & +100 & 10 & 1 & $\mathrm{As}_{6}$ \\
\hline 22.06 & 0.940 & 63 & 38.0 & +100 & 10 & 2 & $\mathrm{As}_{7}$ \\
\hline 23.91 & 1.248 & 65 & 37.1 & 83 & 10 & 3 & $\mathrm{As}_{8}$ \\
\hline 19.26 & 0.474 & 59 & 43.2 & +100 & 15 & 0.5 & $\mathrm{As}_{9}$ \\
\hline 20.03 & 1.119 & 62.5 & 42.6 & +100 & 15 & 1 & $A s_{10}$ \\
\hline 21.93 & 0.976 & 62.7 & 39.5 & +100 & 15 & 2 & $\mathrm{As}_{11}$ \\
\hline 24.16 & 1.127 & 64 & 38.1 & 89 & 15 & 3 & $\mathrm{As}_{12}$ \\
\hline
\end{tabular}




\section{Journal of Education and Science (ISSN 1812-125X), Vol: 29, No: 4, 2020 (1-21)}

نلاحظ من الجدول (3) أن التغيرات التي طرأت على النماذج الأسفلتية المُحورة من حيث إنخفاض قيم النفاذية والاستطالة مع زيادة في نسبة البوليمر المُضاف يمكن أن نُعزي ذلك إلى طبيعة المادة البوليمرية المضافة والتي مزيجج عبارة عن محصلة لصفات مكوناته.

وبصورة عامة يلحظ انه كلما قلت نسبة البوليمر المضافة يؤدي ذلك الى ارتفاع في قيم النفاذية والاستطالة مع انخفاض نوعاً ما في درجة الليونة، مايفسر أن القيم الأعلى التي استخدمت دن البوليمر أدت إلى جعل النظام الأسفلتي أقل تجانساً لذلك كانت نسبة 50.5\% مثالية لهذه المعاملات، كما ان لعامل الزمن تاثير كبير ووأضح على النماذج الأسفلتية إذ أن بزيادة زمن التعرض باشعة المايكروويف مع تقليل نسبة البوليمر المضافة أدت إلى تحسين الخواص الريولوجية بشكل ملحوظ إذ عملت على حصول تذاوب أكبر مابين المواد المتفاعلة مما أدى الى تحسين الخواص الريولوجية للنماذج الأسفلتية . وتم اختيار هذه النسبه من الحفاز اعتمادا على دراسة سابقة تم فيها إثبات ان 0.06٪وزنا من كلوريد الألمنيوم اللامائي هي أفضل نسبه يمكن استخدامها في التفاعلات المتضمنه أثعة المايكرويف كمصدر للطاقة [19].

ان وجود كلوريد الألمنيوم اللامائي في هذا النوع من التفاعلات يعد عامل الكلة قوي يعمل على أحداث تفاعل الكلة بين جزيئات البوليمر المكسر حراريا وجزيئات الاسفلت وهو ما بدى جلياً من ازدياد نسبة الأسفلتين المفصولة والتي ازدادت بازدياد نسبة البوليمر المضاف .

اما بالنسبة للإسفلتين فنلحظ من الجدول (3) أن بزيادة نسبة البوليمر المضاف مع زيادة زمن التعرض لاشعة المايكروويف تزداد نسبة الإسفلتين مقارنة مع أسفلت الاصل اذ ان زيادة نسبة البوليمر المضاف ادت الى زيادة الوزن الجزئي للإسفلت بسبب ارتباط الجزيئات البوليمرية ذات الاوزان الجزيئية العالية بالإسفلت.

3- تحوير الخواص الريولوجية للأسفلت بالمعالجة الكيميائية المحفزة بوجود الكبريت مـع البولي كاربونات باستخدام تقنية المايكروويف:-

إذ تم مزج أسفلت الاصل مع نسب وزنية مختلفة من البولي كاربونات (3,2,1,0.5)\% والمعد حسب الفقرة (1) من الجزء العملي، وإضافة الكبريت بنسبة 1\%، وإضافة نسبة (0.06) \% من حفاز كلوريد الألمنيوم اللامائي، وعند طاقة (360) واط وبأزمان مختلفة، وتم إجراء التحوير كما هو مُبين في الفقرة (3) من الجزء العملي، والجدول (4) يوضح النتائج التي تم الحصول عليها . 
الجدول (4):- المواصفات الريولوجية لأسفلت الدورة المُحور مـع نسب مختلفة من بولي كاربونات، وبوجود نسبة 19 كبريت وبوجود نسبة 0.06 \% من حفاز كلوريد الألمنيوم اللامائي وعند طاقة 360 واط وبأزمان مختلفة.

\begin{tabular}{|c|c|c|c|c|c|c|c|}
\hline الأسفلتين & $\begin{array}{c}\text { الاخترلق } د ل ي ل \\
\text { (PI) }\end{array}$ & الليونة & 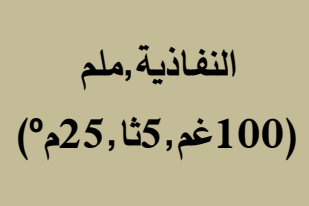 & $\begin{array}{c}\text { الاستطالة } \\
\text { (25,cm) }\end{array}$ & $\begin{array}{l}\text { الزمن } \\
\text { (min) }\end{array}$ & $\begin{array}{c}\text { كاربوناتي } \\
\text { (wt\%) }\end{array}$ & الانموذج \\
\hline 17.81 & -1.448 & 50 & 44.6 & +100 & 0 & 0 & $\mathrm{As}_{0}$ \\
\hline 21.06 & 0.266 & 58 & 43.1 & +100 & 5 & 0.5 & $A s_{13}$ \\
\hline 23.42 & 0.623 & 60 & 42.3 & +100 & 5 & 1 & $\mathrm{As}_{14}$ \\
\hline 27.63 & 0.533 & 59.7 & 41.5 & +100 & 5 & 2 & $A s_{15}$ \\
\hline 29.23 & 1.173 & 64 & 38.8 & 84 & 5 & 3 & $A s_{16}$ \\
\hline 22.16 & 0.638 & 60 & 42.6 & +100 & 10 & 0.5 & $A s_{17}$ \\
\hline 24.79 & 0.619 & 60.3 & 41.2 & +100 & 10 & 1 & $A s_{18}$ \\
\hline 25.23 & 0.928 & 62.5 & 39.3 & +100 & 10 & 2 & $A s_{19}$ \\
\hline 28.61 & 1.025 & 63 & 39.4 & 87 & 10 & 3 & $A s_{20}$ \\
\hline 20.26 & 0.063 & 57 & 43.2 & +100 & 15 & 0.5 & $A s_{21}$ \\
\hline 23.19 & 0.395 & 59 & 41.7 & +100 & 15 & 1 & $A s_{22}$ \\
\hline 24.92 & 0.921 & 62 & 40.8 & +100 & 15 & 2 & $\mathrm{As}_{23}$ \\
\hline 27.34 & 0.834 & 62.3 & 38.3 & 96 & 15 & 3 & $\mathrm{As}_{24}$ \\
\hline
\end{tabular}

As 
نلحظ من الجدول (4) أن إضافة الكبريت بنسبة 1\% أعطت نتائج أفضل من حيث قيم النفاذية ودرجة الليونة، مما يعني أن نسبة التجانس والترابط بين الأسفلت والكبريت والبوليمر عالية عند نسبة 1\% كبريت، وإن نسبة 1\% كبريت كانت أَفضل نسبة بالإمكان استخدامُها لتحوير مواصفات الأسفلت الريولوجية وهذا ما أكدتهُ الدراسات السابقة[29,28]، أما الخواص الريولوجية عند النسب لأبل الاخرى من الكبريت تكون متذبذبة قليلاً وإن أنظمة الأسفلت المُحورة بالبولي كاربونات والكبريت يكون حدوث إنفصال الطور فيها قليل جداً وذلك بسبب تأثير كُلُ واحدٍ على الآخر، وإن إستخدامنا للكبريت في هذه المعالجة سيُزيد من امكانية ارتباط البوليمر مـع جزيئات الأسفلت خلال أواصر كبريتيدية. اما بالنسبة للإسفلتين فنلحظ من الجدول (4) أن بزيادة نسبة البوليمر المضاف مع زيادة زمن التعرض لاشعة المايكروويف تزداد نسبة الإسفلتين مقارنة مع أسفلت الاصل اذ ان زيادة نسبة البوليمر المضاف ادت الى زيادة الوزن الجزيئي للإسفلت بسبب ارتباط الجزيئات البوليمرية ذات الاوزان الجزيئية العالية بالإسفلت.

4- تحوير الخواص الريولوجية للأسفلت بالمعالجة الكيميائية المحفزة مـع بولي كاربونات بدون استخدام تقنية المايكروويف:يعتمد هذا الأسلوب من التحوير على ربط جزيئة البولي كاربونات مع جزيئة الأسفلت واستخدام كلوريد الألمنيوم اللامائي كعامل مُحفز في هذه العملية حيث تحدث العملية بدون استخدام فرن المايكروويف ، ويُبين الجدول(5) نتائج هذه المعالجة.

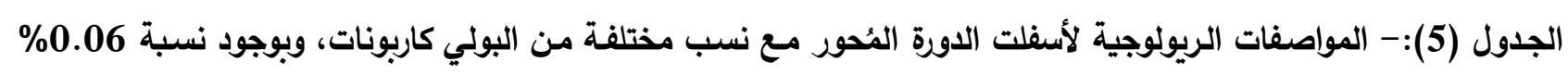

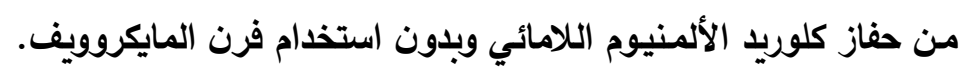

\begin{tabular}{|c|c|c|c|c|c|c|}
\hline الأسفلتين & $\begin{array}{c}\text { الاختراق } \\
\text { (PI) }\end{array}$ & الليونة & 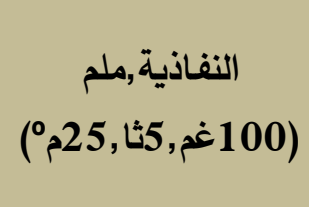 & $\begin{array}{c}\text { الاستطالة } \\
\text { (25,cm) }\end{array}$ & $\begin{array}{c}\text { كاربونات } \\
\text { (wt\%) }\end{array}$ & الانموذج \\
\hline 17.81 & -1.448 & 50 & 44.6 & +100 & 0 & $A s_{0}$ \\
\hline 20.26 & 0.936 & 62 & 41.1 & +100 & 0.5 & $\mathrm{As}_{25}$ \\
\hline 20.97 & 0.980 & 62.5 & 40.2 & +100 & 1 & $\mathrm{As}_{26}$ \\
\hline 22.86 & 1.223 & 64 & 39.7 & 80 & 2 & $\mathrm{As}_{27}$ \\
\hline 23.41 & 1.398 & 65.3 & 38.7 & 76 & 3 & $A s_{28}$ \\
\hline
\end{tabular}

As 
حيث نلحظ من الجدول (5) ان زيادة في نسبة البوليمر (بولي كاربونات) سوف يؤدي ذلك الى تدهور المواصفات الريولوجية، ونلاحظ من خلال الجدول ايضاً أن بزيادة نسبة البوليمر المضاف تقل قيم كل من النفاذية والاستطالة وزيادة في قيم الليونة، وهذا ما يفسر حصول تكتلات في مزيج التفاعل نتيجة ارتباط عدد كبير من البوليمر مع جزيئات الأسفلت بمساعدة كلوريد الألمنيوم اللامائي

كما نلاحظ من الجدول (5) ان بدون استخدام فرن المايكروويف كانت النتائج المحصلة عليها اقل كفاءة مع استخدام المايكرويف، أذ إن استخدام المايكروويف أدت إلى تقليل زمن التحوير من ساعات إلى دقائق مما أدى إلى خفض تكاليف الإنتاج، كما أن استعمال أشعة المايكروويف في التسخين يخفض كمية الغازات المنبعثة أثناء المعالجة مما أدى إلى التقليل من التلوث البيئي، كانت النسبة 5.5\% من البوليمرات المستعملة الأفضل في تحوير الخواص الريولوجية لأسفلت الدورة، إذ لاحظنا أن زيادة نسبة البولي كاربونات المُضافة للأسفلت تُؤدي إلى تدهور المواصفات الريولوجية، وكانت الحساسية الحرارية لجميع النماذج في هذه الدراسة

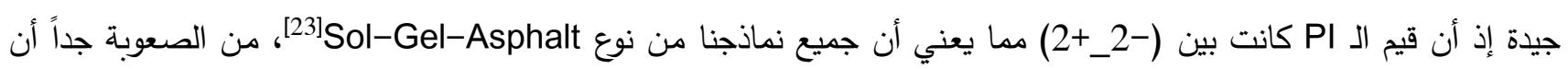
نجد علاقة ثابتة تربط بين المتغيرات التي تطرأ على الأنظمة الأسفلتية أثناء معالجتها بالبوليمرات، وذلك لأن طبيعة التفاعل معقدة

\section{Chemical Immersion Test}

5- 5 اختبار الغمر الكيميائي

هو مقياس أو رقم يُيين مدى التصاق الأسفلت مع الركام وهذا النوع من الفحوصات يبين مقدار مقاومة الأسفلت بعد مزجه بالركام لدرجة الحرارة العالية والأمطار الحامضية [24]، إذ أجريت هذه العملية كما هو موضح بالفقرة(5) من الجزء العملي، والجدول (6) يوضح إنسلاخ (انفصال) الأسفلت عن الركام بالنسبة للأسفلت الأصل (الدورة) والنموذج المحور بتقنية المايكروويف (As9).

الجدول (6):- يوضح قيم إنسلاخ (انفصال) الأسفلت عن الركام بالنسبة لأسفلت الدوة الأصل والمقارنة مـع النموذج المحور

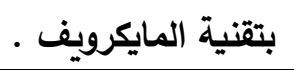

\begin{tabular}{|c|c|c|c|c|}
\hline رقم الانموذج المحور & $\begin{array}{c}\text { R\&W No } \\
\text { للنماذج المحورة }\end{array}$ & $\begin{array}{l}\text { R\&W No } \\
\text { للأسفلت الاصل }\end{array}$ & R\&W No & نسبة Na ${ }^{2} \mathrm{CO}_{3}{ }^{2}$ \\
\hline & & & 1 & 0.025 \\
\hline & $\ldots \ldots$ & & 2 & 0.041 \\
\hline & & 3 & 3 & 0.082 \\
\hline & & & 4 & 0.164 \\
\hline & & & 5 & 0.328 \\
\hline & & & 6 & 0.656 \\
\hline & & & 7 & 1.312 \\
\hline \multirow[t]{2}{*}{$\mathrm{As}_{9}$} & 8 & $\ldots \ldots$ & 8 & 2.624 \\
\hline & & & 9 & 5.248 \\
\hline
\end{tabular}


إذ نلاحظ من القيم في الجدول(6) إن النموذج المحور أكثر مقاومة بكثير من الأسفلت الأصل مما يعني إن النموذج المحور

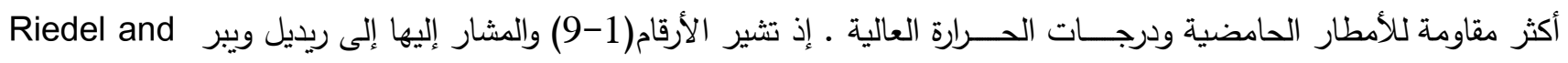
Weber (R\&W) اعلى تركيز ، وهو (5.248) غرام من كربونات الصوديوم (50ml) من الماء. 6- فحص مارشال (Marshall) (التبليط بالأسفلت):-

لغرض معرفة مدى مُلاءمة النماذج الأسفلتية لأغراض التبليط تم إجراء فحص المارشال التبليط بالأسفلت) للنموذج المحور بتقنية المايكروويف(As9) والتي كانت مواصفاتها مُطابقة لمواصفات هيئة الطرق والجسور العراقية (S.O.R.B) لعام 2001 كأسفلت تبليط[25]، وأيضاً للأسفلت الأصل، إذ تم الفحص كما هو مُبين في الجدول (7) • الجدول (7):- - يوضح قيم الاستقرية والزحف لأسفلت الدورة المُحقّر والمقارنة مـع أسفلت الدورة الأصل، ومواصفات هيئة (S.O.R.B) الطرق والجسور)

\begin{tabular}{|c|c|c|c|}
\hline $\begin{array}{l}\text { الزحف) } \\
\text { (mm) }\end{array}$ & $\begin{array}{c}\text { الإستقرارية } \\
\text { (KN) }\end{array}$ & نسبة الأسفلت (\%) المضاف إلى الركام & رقم النماذج الأسفلتية \\
\hline 5.1 & 11.3 & \multirow[b]{2}{*}{4.5} & $\mathrm{As}_{0}$ \\
\hline 3.5 & 16.4 & & $\mathrm{As}_{9}$ \\
\hline $4-2$ & $\begin{array}{c}7 \\
\text { Minimum }\end{array}$ & $5.5-3$ & $\begin{array}{c}\text { مواصفات } \\
\text { (S.O.R.B) }\end{array}$ \\
\hline
\end{tabular}

يتضح من الجدول (7) أن قيمة الاستقرارية للأسفلت الأصل كانت ضمن مواصفات هيئة الطرق والجسور العراقية (S.O.R.B) كأسفلت تبليط[25]، ولكن قيمة الاستقرارية للنموذج الأسفلتية المحور كانت أفضل بكثير من قيمة الاستقرارية للأسفلت الأصل إذ نلاحظ ارتفاع في قيمتها وهذا مؤشر جيد على قدرة مقاومة التبليط للتشوه الناتج عن تعرض الطريق للأحمال المُتكررة لوسائط النقل . ولكن قيمة الزحف للأسفلت الأصل كانت خارج مواصفات هيئة الطرق والجسور العراقية (S.O.R.B) كأسفلت تبليط وهذا ما يفسر تعرض الشوارع المبلطة بأسفلت الدورة دون معالجة الى التخدد والروطان مما يسبب تبعات اقتصادية سيئة من استخدامه في التبليط بدون اجراء المعالجات والتحويرات اللازمة لهُ.

وبينما قيم الزحف للنموذج الأسفلتي المُحور كان افضل بكثير من قيمة الزحف للأسفلت الأصل إذ نلاحظ انخفاض في قيمتها مما يجعلهُ أكثر مقاومة وثباتاً الزحف عند تعرض الطريق للأحمال المُتكررة لوسائط النقل وهذا يعطي مؤشراً يُشير إلى أن المزيج ذو 
نسبة فراغات قليلة، إذ نجد أن النموذج المحضرة أفضل بكثير من أسفلت الأصل الذي يكون عرضة للتشوه الابتدائي[30,25]، وهذا ما يُفسر تعرض الكثير من الطرق المُبلطة اليوم بهذا النوع من الأسفلت للزحف وعدم الاستقرارية.

7- اختبار الفرن لاغثية الأسفلت الرقيقة (Thin Film Oven Test)

حيث تم اجراء هذ الاختبار على كل من النموذج الاصل والمُحور، حيث كانت النتائج المحصل عليها على وفق الجدول (8).

الجدول (8):- تفيير الموصفات الريولوجية لأسفلت الدورة المحور وأسفلت الدورة الاصل بعد اخضاعهما لفحص الفرن لأغشية (TFOT) الأسفلت الرقيقة

\begin{tabular}{|c|c|c|c|}
\hline بعد الفحص & قبل الفحص & الصفات الريولوجية & رقم النموذج \\
\hline 53 & 50 & درجة الليونة(مº) & \\
\hline 41.3 & 44.6 & النفاذية (100غم ,5ثا, 25 مº) & \\
\hline+100 & +100 & الاستطالة (سم ,25 مم) & $A s_{0}$ \\
\hline-0.909 & -1.448 & دليل الاختراق (PI) & \\
\hline 0.05 & -------- & نسبة الفقدان بالوزن \% & \\
\hline 62.3 & 59 & درجة الليونة(مº) & \\
\hline 41.7 & 43.2 & النفاذية (100غم ,5ثا, 25 مº & \\
\hline+100 & +100 & الاستطالة (سم ,25 م²) & $\mathrm{AS}_{9}$ \\
\hline 1.033 & 0.474 & دليل الاختراق (PI) & \\
\hline 0.031 & --------- & نسبة الفقدان بالوزن \% & \\
\hline
\end{tabular}

نلحظ من الجدول (8) أن درجة تأثر الأسفلت المُحور بظروف التقادم الزمني من درجة حرارة و أوكسجين بشكل عام تكون قليلة، ويعد هذا امراً ايجابياً ونستال من هذا ان النموذج الأسفلتي المحور يمتاز بمقاومة كبيرة للاجهادات وتشققات اقل فضلاً عن العمر التثغيلي الطويل، وأن عدم تأثر النموذج الأسفلتي الدُحور بظروف التقادم الزمني يعزى الى ما يتمتع به البولي كاربونات الذي يعمل على تحسين الخواص الميكانيكية والمتمثلة بزيادة متانة النموذج الأسفلتي وتحمله للاجهادات وتقليل التكسير الحراري وزيادة مقاومته لتكوين الاخاديد [32,31].

وبالرجوع إلى الجداول السابقة (3) ,(4) ,(5) نجد أن هناك بعض النماذج المعالجة يمكن استخدامها كأسفلت تبليط بعد إخضاغُها للاختبارات الهندسية الهناسبة، ووجد أيضاً أن بعض النماذج الأخرى تميزت بدرجات ليونة عالية وقيم نفاذية واستطالة

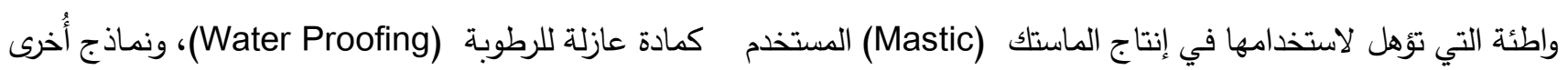
بالإمكان استخدامُها كأسفلت يُستخدم في التسطيح. 
والجدول (9) يُبين قيم النفاذية والاستطالة ودرجة الليونة للأسفلت المستخدم كماستك عازل للرطوبة وحسب المواصفات القياسية

الأمريكية ASTM(D491-41) المعتمدة عالمياً

الجدول (9):-المواصفات القياسية الأمريكية(ASTM(D491-41 للأسفلت المُستعمل لإنتاج الماستك

\begin{tabular}{|c|c|c|}
\hline الحد الأعلى & الحد الأدنى & القياسات الريولوجية \\
\hline 65 & 54 & درجة الليونة (مº) \\
\hline 40 & 20 & النفاذية، ملم (100غم، 5ثا، 25م \\
\hline . & 15 & الاستطالة (سم، 25مم) \\
\hline
\end{tabular}

أما المواصفات القياسية العراقية للأسفلت المُستعمل لأغراض التسطيح فيبينها الجدول (10)

الجدول (10):-المواصفات القياسية العراقية للأسفلت المُستعمل في التسطيح

\begin{tabular}{|c|c|c|}
\hline الحد الأعلى & الحد الأدنى & القياسات الريولوجية \\
\hline 66 & 57 & درجة الليونة (مº) \\
\hline 40 & 18 & النفاذية، ملم (100غم، 5ثا، 25مº \\
\hline . & 10 & الاستطالة (سم، 25م²) \\
\hline
\end{tabular}

والجـــدول (11) يُبين الخواص الـــريولوجية لأسفلت التبليط علـــى وفق مواصفات هـــيئة الطرق والجسور

العراقية)(S.O.B.R) لعام 2001

الجدول (11):-يبين الخواص الريولوجية للأسفلت المُستعمل في التبليط

\begin{tabular}{|c|c|c|}
\hline الحد الأعلى & الحد الأدنى & المواصفات الريولوجية \\
\hline . & 100 & الاستطالة (25،cmمم) \\
\hline 50 & 40 & النفاذية ،ملم (100 غم.5ثا.25مº) \\
\hline 60 & 51 & درجة الليونة (مº) \\
\hline
\end{tabular}

Conclusion

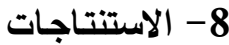

نستطيع بعد انتهاء من دراستتا هذه أن نوجز أهم الاستنتاجات التي تم التوصل إليها والتي تعد المحصلة النهائية لعملية البحث المنجز في هذه الدراسة:- 
a) إن استخدام تقنية التسخين بالمايكرويف (Microwave) أدت إلى تقليل زمن التحوير من ساعات إلى (إنى دقائق مما أدى إلى خفض تكاليف انتاج النماذج الأسفلتية، كما إن إستعمال أشعة المايكروويف في التسخين يخفض كمية الغازات المنبعثة أثناء المعالجة حيث يؤدي إلى التقليل من التلوث البيئي.

b كانت النسبة(0.5)\% من البوليمر المستخدمة الأفضل في تحوير الخواص الريولوجية لأسفلت الدورة إذ

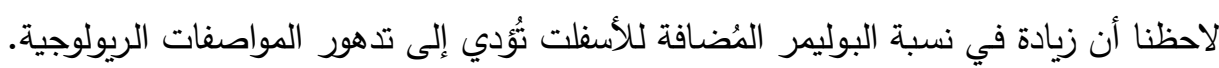

C ) إن إضافة(1)\% من الكبريت تعمل على تحسين الخواص الريولوجية لأسفلت الدورة بصورة ملحوضة وهذا

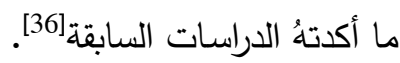

) من الصعوبة أن نجد علاقة ثابتة تربط بين المتغيرات التي تطرأ على الأنظمة الأسفلتية أثناء معالجتها بالبوليمرات وذلك لأن طبيعة التفاعل الذي يحدث يكون معقدة جداً.

e أن نجاح بعض النماذج المُحورة في اختبارات مارشال والتقادم مؤشراً إيجابياً على إمكانية استخدام هذه

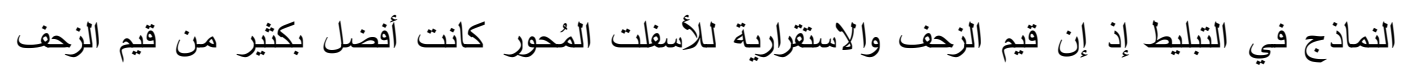
والإستقرارية للأسفلت الأصل.

f ) إن الأسفلت المُحور يمتلك قيم انسلاخ أعلى من الأسفلت الأصل مما يعني ان الأسفلت المُحور أكثر مقاومة

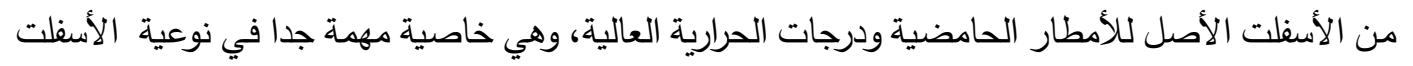
التي تمكن الأسفلت المُحور من الالتصاق بصورة اكبر مـع الركام مما يعطي عمراً تشغيلياً اكبر للشوارع ومقاومة اعلى.

(Acknowledgement ) : شكر وتقدير )

يتقدم الباحثون بالثكر والتقدير لقسم الكيمياء في كلية التربية للعلوم الصرفة - جامعة الموصل والى كلية الهنسة جامعة الموصل لتقديم التسهيلات اللازمة لاكمال هذا البحث .

(المصادر: (References)

1- Schmerling,L. ,"Encyclopedia of Science and Technolog ".Vol.10,5 ${ }^{\text {th }}$ ed.,Mc GrawHill,Inc.,New York,pp.76 . (1982).

2- Hobson, G.D. "Modern Petroleum Technology".4 $4^{\text {th }}$ ed., Ltd. Britain, pp.804-806,(1973).

3- Ramadan, M.A. Al-Ghannam Dhanun A., "Industrial Chemistry and Industrial Pollution”, Dar Al-Kutub for Printing and Publishing, University of Mosul, pp. 108-106119, 421, 465-469, 524,523. (1991). 
4- Asphalt Institute Inc. and European Bitumen Association, Eurobitume, (2015), The Bitumen Industry, A Global Perspective, $3^{\text {rd }}$ ed., USA.

5- "Introduction to asphalt" , Asphalt Institute Manual Series No.5(MS-5)p.2,9$11,14,61$. (2001).

6- Lesueur D., Advances in Colloid and Interface Science, pp. 145, 28-42. (2009).

7- Al-Ghannam K.A.A., Ph.D. Thesis, University of Mosul. (1996)

8- Murshid, D.M., Tishreen University Journal for Research and Scientific Studies, Volume (37), No. 1, pp. 331-. 317. (2015).

9- Abbas, T.H., Saeed, SM, Kamel, F.H., Khaled, SAL, Numan, R., The Journal of Iraqi Industrial Research, Volume (3), No. (1), Pp. 45-41. (2016).

10- Muhammed, P.M. , Master Thesis, University of Mosul. (2017).

11- Nekhoroshev, V. P., Nekhoroshev, S. V., Nekhorosheva, A. V., and Tarasova, O. I., Petroleum Chemistry, 57(8), 643-648. (2017).

12- Rabi', M.A., Hamdoun, A.A., Proceedings of the first international and third scientific conference of the College of Science - Tikrit University / December 17-18 (c5), pp. 87-92. (2017).

13- Sultan, b. Tishreen University Journal-Engineering Sciences Series, Vol. 40, No. 6. (2018).

14- Yu, J., Ren, Z., Yu, H., Wang, D., Svetlana, S., Korolev, E., and Guo, F., Materials, 11(11), 2093. (2018).

15- Lin, Y., Hu, C., Adhikari, S., Wu, C., and Yu, M. ,Applied Sciences, 9(6), 1242. (2019).

16- Yu, J., Ren, Z., Gao, Z., Wu, Q., Zhu, Z., and Yu, H., Polymers, 11(5), 800. (2019). 
17- Hussein, A.A., Hamdoon, A.A., Journal of Education and Science, Volume (28), No. 40-49. (2019).

18- Khavandi Khiavi, A., Ghanbari, A., and Ahmadi, E., Journal of Materials in Civil Engineering, 32(3), 04020010.(2020).

19- Al-Altwahi, H.S., Master Thesis, University of Mosul. (2014).

20- American Society for Testing and Materials, Part II, (D36-70), P.27 (1972).

21- American Society for Testing and Materials, Section 4, (D5-83),P .97 (1986).

22- $\quad$ American Society for Testing and Materials, Section 4, (D5-85),P .127 (1986).

23- Traxler, R. N., “ Asphalt: Its Composition, Properties in Uses”, Haff, Ltd., London, p. 3. 72-72, (1961).

24- Chemical Immersion Standard Method TMH1(Road Research Laboratory 1986 ,England).

25- "Specifications of the Roads and Bridges Authority (S.O.R.B)", Republic of Iraq - Ministry of Housing and Construction - Department of Studies and Designs Baghdad - 2001.

26- Asphalt Institute, (1984), "Mix Design Method for Asphalt Concrete and other Hot - Mix Design". MS - 2 .

27- American Society for Testing and Materials D1754-97R(2002),Section 4,Vol.04 .03, Road and paving materials-vehicls-pavement systems, New york.

28- Mahal A.S.A., Master Thesis, University of Mosul. (2000).

29- Afzal, M. and Nasser, A., Pakistan, J. Sci. Ind. Res., Vol.15, No.3, pp.137-139. (1972).

30- American Society for Testing and Materials D113-99,Section 4, Vol .04 .03, Road and paving materials-vehicle-pavement systems ,New york. 
Journal of Education and Science (ISSN 1812-125X), Vol: 29, No: 4, 2020 (1-21)

31- Navarro F.J., Partal P. and Martinez- Boza F ., Fuel,2041-2049.(2004)

32- $\quad$ Becker Y. ;Menderz M.p. and Rodriguez Y., Vision Technological, Vol. 9, No. 1,pp 39-50 . (2001).

33- American Society for Testing and Materials,Part II,(D491-41),p.250-251 (1969).

34- Standard No. 1196 of 1988 issued by the Central Organization for Quality Measurement and Control of the kair used for flattening.

35- Specification of Roads and Bridges Authority (S.O.R.B) Republic of Iraq Ministry of Housing and Construction - Department of Studies and Designs Baghdad -1990.

36- Saleh, L.A., Master Thesis, University of Mosul. (1992). 